\title{
$\mathrm{VDT}$ 작업에서의 근골격계 질환 예방을 위한 새로운 팔 지지대 제안 \\ 박경수 · 홍기범 · 김상수 · 조일행 \\ KAIST 산업공학과
}

\section{Proposal of a Movable Armrest for Preventing the Musculoskeletal Disorders}

\author{
Kyung Soo Park, Gi Beom Hong, Sang Soo Kim, Il Haeng Cho \\ Department of Industrial Engineering, KAIST, Daejeon, 305-701
}

\begin{abstract}
In spite of the rapid increase of computer use in our everyday life, not much effort is undertaken to take measures to prevent Musculoskeletal Disorders(MSDs). In this paper, we suggest a movable armrest which would lower the exposure to the MSDs, especially on the vicinity of arm. The aim of this study is to determine whether there are differences in wrist angle variations, forearm muscular loads, comfort and normal performance between the invented movable armrest and a conventional armrest when using a computer mouse. Eight experienced VDU workers performed a standardized simple task set which consists of 15 detailed tasks with each armrest. The wrist angle variations in the right arm were registered by electrogoniometer and the muscle activities in the shoulder, deltoid and two extensors in the forearm were also registered by electromyograph. The subjects rated perceived comfort while performing the tasks with each armrest. Working with the invented armrest, compared to general, gave significantly decreased wrist angle variations at most of the detailed tasks of both biaxial movements. Moreover, as the distance of targets increased, the difference of muscle activities in two different situations trend to be increasing. At the same time, in work with invented armrest, the subjects rated more comfort and they showed decreased normal performances in 8 detailed tasks which were mainly caused by macro moving time.
\end{abstract}

Keyword: Armrest, Musculoskeletal disorders, EMG, Electrogoniometer

1. 서 론

한국 인터넷 정보센터의 보고서에 따르면 국내 2004년 상반기 컴퓨터 이용시간이 일주일에 1 인당 평균 14.6 시간이 라 한다. 이처럼 컴퓨터는 이미 보급 정도를 뛰어넘어 우리 의 일상 생활 속에 자리매김하고 있다. 컴퓨터로 인해 여러 가지 작업에 있어 많은 부분이 편리하게 되었지만, 근래에

\begin{abstract}
들어 지속적인 컴퓨터의 사용으로 인한 근골격계 질환이 새로운 직업병으로 인식되고 관심이 집중되고 있다. 몇 년 전까지만 해도 산업현장에서의 인력운반(Manual materials handling: $\mathrm{MMH}$ ) 작업에서 주로 발생하는 질병으로 여겨졌 던 이러한 질환은 최근 'VDT (Visual display terminal) 증후 군'이라는 이름 하에 목, 어깨, 상박, 하박, 손목, 손, 손가락 등에서 지속적으로 관찰되고 있으며, 급격한 증가세를 나타 내고 있다.
\end{abstract}

교신저자: 박경수

주 소: 305-701 대전광역시 유성구 구성동 373-1, 전화: 042-869-3152, E-mail: kspark@kaist.ac.kr 
오늘날 VDT환경하에서 입력장치로서 가장 많이 이용되는 것은 키보드와 마우스이며, 컴퓨터가 발달될수록 마우스에 대한 의존도가 점점 높아져가고 있다(Cooper et al., 1998). 몇몇의 연구에 따르면 컴퓨터 마우스 이용이 상지에 유발 되는 근골격계 질환과 관련이 있다고 이야기하고 있으며 (Armstring et al., 1994; Rempel et al., 1994), 일련의 근육 부하(muscle load) 또한 근골격계 질환과 관련이 있다고 이 야기하고 있다(Karlqvist et al., 1996; Jensen et al., 1998; Cooper and Straker, 1998). 더욱이 전통적인 마우스는 주 로 손목을 이용해 움직이게 되어 있는데 이와 같은 지속적 이고 반복적인 동작은 누적외상성장애(Cumulative Trauma Disorders, CTDs)를 야기할 위험을 지니고 있다. 실제로 24명의 VDU-worker들을 대상으로 실험한 한 연구에 따 르면 모든 피실험자들에게 키보드보다 마우스에서 더 큰 척 골편위 (ulnar deviation) 가 나타났다(Karlqvist et al., 1994). 큰 척골편위에 장시간 노출되면 일반적인 누적외상병 중 하 나인 건초염(Tenosynovitis)에 걸릴 위험이 증가하고, 심하 면 건염(Tendinitis)으로 발전할 수 있다. 또한 반복적인 손목의 굴곡(flexion) 과 신장(extension)은 수근관 증후군 (Carpal tunnel syndrome)을 야기시키는 원인으로 알려져 있다.

이처럼 컴퓨터 사용은 날로 그 비중이 높아지고 있지만 그에 따라 발생할 수 있는 여러 가지 근골격계 질환들과 관 련하여, 이를 줄이고 예방할 수 있게 하기 위한 노력은 매우 미미한 실정이다.

이에 따라 본 연구의 목적은 크게 두 가지이다. 먼저 VDT작업 중 일반적인 팔 지지대를 이용하여 마우스를 사 용할 경우 야기되는 근육부하 및 손목 움직임을 정량화된 과제를 통해 측정하여 측정부위 별, 수행 과제 별로 비교해 보고 어떤 차이를 보이는지, 차이가 유의한지를 분석하여 추 후 관련 연구의 기초자료로 활용될 수 있도록 하며, 다음으 로 근골격계 질환 예방을 위해 제안한 새로운 팔 지지대를 기존의 팔 지지대와 비교하고 검증해 보는 것이다.

\section{2. 고안 및 일반 팔 지지대 소개}

[그림 1]의 위쪽 평면과 정면사진은 고안된 팔 지지대이 다. 사진과 같이 고안된 팔 지지대는 크게 '팔 받침대'(27 $\times 8 \times 2.3 \mathrm{~cm})$ 와 받침대 아래의 '움직임 판' $(36 \times 15 \times 1.5$ $\mathrm{cm}$ )으로 구성되어 있다. 팔 받침대에는 4 개의 볼 케스터와 한 개의 바퀴가 있으며, 움직임 판은 뒤쪽의 팔 지지 축을 포함하고 있어 사용자가 팔을 기대어 움직일 수 있도록 설계 하였다.
고안된 팔 지지대는 팔 받침대가 움직일 수 있도록 하여, 손목과 손가락 사용을 줄이도록 설계되었고 기존의 팔 지지 대처럼 팔이 기댈 수 있도록 움직임 판 뒷부분에 팔 지지 축 을 포함한 것을 특징으로 한다.

또한 [그림 1]의 아래쪽 평면과 정면사진은 일반 팔 지지 대이며, 고안 팔 지지대와 같은 높이와 재질로 고정되도록 설계해 이로 인한 오차를 배제하였다.

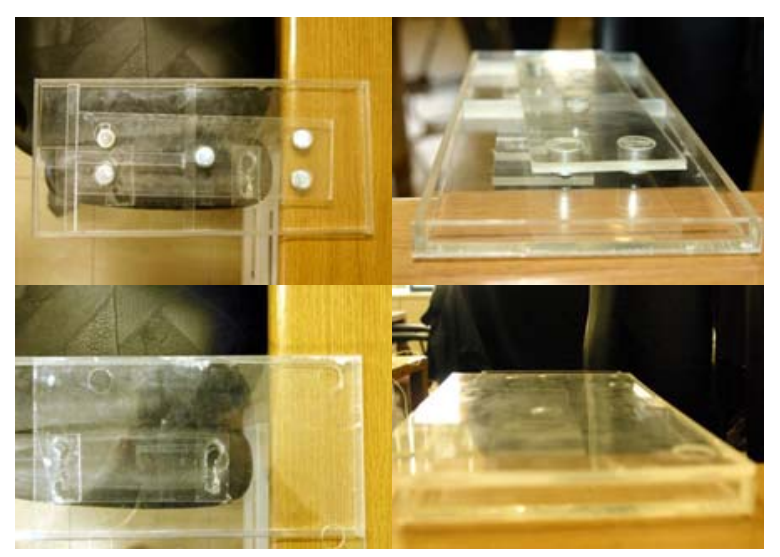

그림 1. 고안 및 일반 팔 지지대

\section{3. 실 험}

\section{1 피실험자}

성별에 따른 차이를 없애기 위해 8명의 건강한 남자 대학 원생(나이 평균 29.125세; 24 35세)이 실험에 참여하였 다. 피실험자는 마우스 사용 경험이 풍부(하루 평균 4.75 시 간)하고 많은 시간(하루 평균 6.06시간)을 컴퓨터 작업에 할애하는, 평상 시 모두 오른손으로 마우스를 사용하는 사 람들로 구성되었다. 실험 전 피실험자들에게 고안된 팔 지지 대의 사용법을 상세히 설명하였고, 사전 연습시간(30분 1 시간)을 주어, 개인 별 편차를 줄이고 실험의 정확성을 높 였다.

\section{2 과 제}

과제는 크게 [그림 2] 와 같이 5그룹으로 나뉘고 각 그룹 당 [그림 3] 과 같이 3수준을 포함, 총 15 가지의 세분화된 과제를 1 세트로 수행하였다. 1 4번 그룹까지의 각 세분화 된 과제는 과제 시작 시 화면에 나타나는 한 개의 아이콘 $(40 \times 40$ pixe $)$ 을 마우스로 클릭하면 반대편에 다시 한 개 의 아이콘이 나타나고 클릭 시 다시 반대편 처음 위치에 아 
이콘이 나타나는 과정의 반복으로 이루어져 있으며, 5 번 그 룹 과제의 경우 그림 2에서처럼 8방향 모두에서 랜덤하게 아이콘이 나타나도록 하였다.

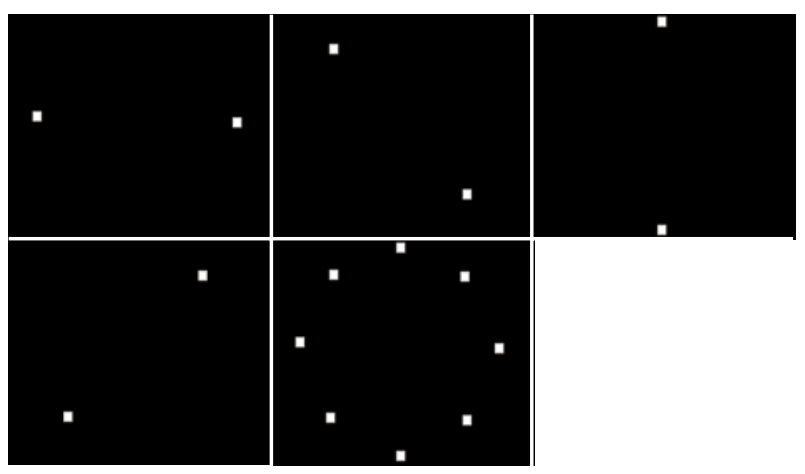

그림 2. 왼쪽 위부터 차례로 과제 1-3, 과제 2-3, 과제 3-3, 과제 4-3, 과제 5-3

[그림 3]은 1 번 그룹의 3가지 수준에 대한 예시이다. 아 이콘 중심과 중심 사이의 거리를 120 pixel, 240pixel, 480 pixel로 각각 $1,2,3$ 수준을 설정하였다.
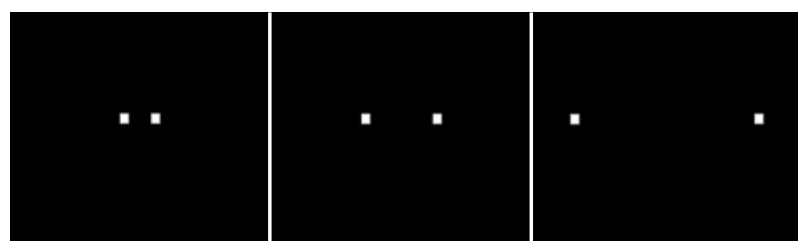

그림 3. 왼쪽부터 차례로 과제 1-1, 과제 1-2, 과제 1-3

이에 따라 과제의 표기는 앞으로 '그룹번호-수준번호' (ex 3-2: 3그룹의 2수준)로 표기하고, 15 가지 각각의 component들을 '세부 과제', 한 Experimental unit에 포함 되는 15 개 component들의 묶음을 '전체 과제' 또는 '과제' 라 칭하도록 하겠다.

전체 과제 구성은 각 세부 과제당 3 분씩, 과제 시작 및 세부 과제 사이에 5 초 간의 휴식을 둔 형태로 총 46 분 15 초 $(3$ 분 $\times 15$ 세부 과제 +5 초 $\times 15$ 회 $)$ 를 한 세트로 하여 피실 험자의 수에 맞게 총 8개의 과제 세트를 구성하였다. 세트 내의 세부 과제 순서는 랜덤하게 정하였다.

\section{3 실험 설계}

피실험자는 준비된 8 개 과제 세트 중 선택된 1 개의 과제 를 balanced된 랜덤 순서로 고안된 팔 지지대와 일반 팔 지 지대 각각에서 평소의 마우스 움직임과 같은 속도로 수행하
도록 지시 받았다. 각 실험은 개인별로 하루 안에 이루어졌 으며 고안과 일반 팔 지지대 실험 사이에 최소 1 시간 이상 의 시간차이를 두어 혹시 있을지 모르는 'after effect'를 제 거하였다.

과제를 수행하는 동안 과제 수행시간 및 세부 과제 별 클 릭횟수가 저장되었고, electrogoniometer를 통해 손목 각 의 변화를 좌우, 위아래 두 개의 채널로 측정하였다. 또한 $\mathrm{EMG}$ (electromyograph)를 통해 오른쪽 어깨 및 팔의 근육 활동을 네 부위 (upper trapezius, anterior deltoid, extensor digitorum, extensor carpi ulnaris; 이하 UT, $\mathrm{AD}, \mathrm{ED}$, $\mathrm{ECU}$ 로 표기)에서 측정하였다.

마지막으로 피실험자들은 각 과제 세트가 끝날 때마다 bipolar scale $(-4$ 부터 +4$)$ 로 구성된 주관적 편안함을 부위 별로 작성하였다(Karlqvist et al., 1995).

\section{4 측정 방법}

\subsection{1 손목 움직임}

손목 각 움직임 측정을 위해 Twin axis electrogoniometer와 data logger(DA100C, MP100A; BIOPAC Systems, Inc.) 가 사용되었다. 이를 통해 손목의 요측/척측(radial/ ulnar) 편차 및 굴곡/신장(flexion/extension)을 기록하였 다. Goniometer는 매뉴얼에 따라 오른쪽 팔의 손등 방향 에 고정시켰다.

피실험자 별로 마우스를 잡은 편안한 자세에서의 손목의 영점이 조정되었고, 좌우, 위아래 각각 $20^{\circ}$ 만큼 움직인 상 황에서의 값들이 기록되어 scaling되었다. Sampling rate은 $16 \mathrm{~Hz}$ 이고, data는 측정 시스템에서 $\mathrm{PC}$ (Pentium 4 1.8G, 512RAM)로 옮겨진 뒤 Acknowledge 3.8.1라는 소프트 웨어를 통해 분석되었다.

세부 과제 별로 처음 30초와 나중 30초를 제외한 2분 동 안 기록된 data는 $0.5 \mathrm{~Hz} 2 \mathrm{~Hz}$ 로 band pass filtering 되었 고, RMS변환을 한 뒤 peak값들의 양측 $10 \%$ 는 잡음이라 가 정하여 제거하고, 왕복한 cycle당의 평균 손목 각 변화량이 계산되었다.

\subsection{2 근육부하}

EMG(EMG 100C,MP100A; BIOPAC Systems, inc.)를 통해 오른쪽 팔 $\mathrm{UT}, \mathrm{AD}, \mathrm{ED}, \mathrm{ECU}$ 네 부위의 근육 활동이 측정되었다.

전극은 중심 사이의 거리가 $20 \mathrm{~mm}$ 인 $\mathrm{EMG}$ 전용 전극 $(\mathrm{EL}$ 504, BIOPAC Systems, inc.) 을 사용하였고, 면도된 마른 피부를 알코올 솜으로 닦은 뒤, 사포로 가볍게 문지른 후, 젖은 거즈로 닦아 말린 후 피부에 부착하였다.

세부 과제 별로 처음 30 초와 나중 30 초를 제외한 2 분 동 
안의 신호를 분석에 사용하였고, Sampling rate은 $1024 \mathrm{~Hz}$ 이며, $20 \mathrm{~Hz} ~ 500 \mathrm{~Hz}$ 의 band pass filtering후 UT와 $\mathrm{AD}$ 의 경우 RVC(Reference voluntary contraction)를, ED와 ECU의 경우는 MVC(Maximum voluntary contraction)를 측정하여 정규화에 이용하였다(Gustafsson et al., 2003; Cook et al., 2004). RVC의 측정은 UT의 경우 $2.5 \mathrm{~kg}$ 의 추를 팔꿈치를 편 채 외전 $90^{\circ}$ 의 각도로 수직으로 들어올려 15 초씩 2회 측정하였고, $\mathrm{AD}$ 의 경우 $\mathrm{UT}$ 와 같은 무게의 추 를 팔꿈치를 편 채 굴곡 $90^{\circ}$ 의 각도로 손목을 최대로 외전 시킨 자세로 15초씩 2회 측정하였다(Cook et al., 2004). 그 리고, $\mathrm{ED}$ 와 $\mathrm{ECU}$ 의 경우 각각 손의 아래에서 위쪽으로, 손 의 왼쪽에서 오른쪽 바깥으로 5초간 2회씩 힘을 주어 static 상태에서의 MVC값을 구하였다(Gustafsson et al., 2003). 이를 통해 \%RVC 또는 \% MVC를 각각 계산하였다.

\subsection{3 주관적 편안함}

피실험자들은 각 세트의 실험이 끝날 때 마다 목, 어깨, 상박, 하박, 손목, 손, 손가락, 총체적 편안함 총 8 부위로 나누어 Bipolar scale로 -4 (very poor comfort)에서 4 (extremely comfort)까지 점수를 부여하여 분석에 이용하 였다(Karlqvist et al., 1995).

\subsubsection{Normal performance}

평상 시의 마우스 사용과 동일한 속도로 과제를 수행하였 을 때 각 세부 과제 별로 3 분 동안 클릭하는 클릭회수를 가 리켜 'Normal performance'라 정의하고 이를 세부 과제 별 로 일반 및 고안 팔 지지대에서 각각 측정하였다. 또한 [식 1] 에 의거 Normal performance ratio(NP ratio) 값을 구 해 보았다.

$$
\text { NP ratio }=\frac{\text { 고안 팔 지지대의 클릭회수 }}{\text { 일반 팔 지지대의 클릭회수 }} \times 100
$$

[식 1] Normal performance ratio

\section{4. 실험 결과 및 분석}

\section{1 손목 움직임}

\subsection{1 손목 좌우 움직임}

실험 결과 표 1 에서와 같이 각 그룹의 세부 과제 중 [1-3], [2-2, 2-3], [3-1, 3-2, 3-3], [4-2, 4-3], [5-2, 5-3] 에서 고안 팔 지지대의 좌우 손목 각 변화량 이 적다는 유의한 차이를 나타내었다.
표 1. Paired T-Tests 후의 손목 좌우 움직임 평균과 $95 \%$ 신뢰구간 및 $p$-value $(\mathrm{n}=8)$

\begin{tabular}{lrrrrl}
\hline \multirow{2}{*}{ 과제 } & \multirow{2}{*}{$\begin{array}{c}\text { 고안 평균 } \\
\left(^{\circ}\right)\end{array}$} & 일반 평균 & \multicolumn{2}{c}{$95 \% \mathrm{CI}$} & \multirow{2}{*}{$p^{\text {-value }}$} \\
\cline { 4 - 5 } $1-1$ & 9.18611 & 10.29029 & -4.19 & 6.40 & 0.6371 \\
\hline $1-2$ & 14.15970 & 17.83115 & -4.36 & 11.71 & 0.3158 \\
\hline $1-3$ & 16.46103 & 24.63264 & 0.85 & 15.49 & $0.0335^{* *}$ \\
\hline $2-1$ & 8.76057 & 10.66657 & -1.26 & 5.07 & 0.1972 \\
\hline $2-2$ & 8.21257 & 15.89817 & 2.93 & 12.44 & $0.0065^{* *}$ \\
\hline $2-3$ & 9.81157 & 20.98573 & 3.97 & 18.38 & $0.0080^{* *}$ \\
\hline $3-1$ & 5.82272 & 7.96642 & -0.37 & 4.65 & $0.0832^{*}$ \\
\hline $3-2$ & 3.71017 & 8.06380 & 0.96 & 7.75 & $0.0191^{* *}$ \\
\hline $3-3$ & 6.23448 & 12.11018 & 3.59 & 8.16 & $0.0005^{* *}$ \\
\hline $4-1$ & 8.10896 & 9.88201 & -2.54 & 6.08 & 0.3630 \\
\hline $4-2$ & 5.08615 & 8.88033 & 0.94 & 6.65 & $0.0164^{* *}$ \\
\hline $4-3$ & 7.23230 & 10.84835 & -0.77 & 8.00 & $0.0920^{*}$ \\
\hline $5-1$ & 5.90864 & 7.39585 & -0.95 & 3.92 & 0.1915 \\
\hline $5-2$ & 8.07053 & 12.69806 & 2.70 & 6.56 & $0.0008^{* *}$ \\
\hline $5-3$ & 7.02962 & 14.59167 & 3.67 & 11.45 & $0.0025^{* *}$ \\
\hline
\end{tabular}

*significant at 0.1 level; **significant at 0.05 level

\subsection{2 손목 위아래 움직임}

실험 결과 표 2 에서와 같이 각 그룹의 세부 과제 중

표 2. Paired T-Tests 후의 손목 위아래 움직임 평균과 $95 \%$ 신뢰구간 및 $p$-value $(\mathrm{n}=8)$

\begin{tabular}{lrrrrl}
\hline \multirow{2}{*}{ 과제 } & \multirow{2}{*}{ 고안 평균 } & \multirow{2}{*}{ 일반 평균 } & \multicolumn{2}{c}{$95 \% \mathrm{CI}$} & \multirow{2}{*}{${ }^{\text {-value }}$} \\
\cline { 4 - 5 } & & & lower & upper & \\
\hline $1-1$ & 2.65240 & 4.23270 & -1.49 & 4.09 & 0.3063 \\
\hline $1-2$ & 4.97346 & 5.76382 & 0.05 & 2.71 & $0.0434^{* *}$ \\
\hline $1-3$ & 5.59160 & 7.71718 & 0.66 & 5.09 & $0.0108^{* *}$ \\
\hline $2-1$ & 4.98426 & 6.63081 & -0.84 & 4.14 & 0.1619 \\
\hline $2-2$ & 4.97316 & 8.55912 & 0.21 & 6.96 & $0.0403^{* *}$ \\
\hline $2-3$ & 5.06298 & 8.60675 & 0.39 & 6.70 & $0.0327^{* *}$ \\
\hline $3-1$ & 5.72877 & 9.20587 & 0.81 & 6.14 & $0.0177^{* *}$ \\
\hline $3-2$ & 4.79190 & 8.14149 & 0.41 & 6.29 & $0.0311^{* *}$ \\
\hline $3-3$ & 5.03915 & 11.22213 & 2.05 & 10.31 & $0.0095^{* *}$ \\
\hline $4-1$ & 4.38483 & 6.62422 & -0.73 & 5.21 & 0.1182 \\
\hline $4-2$ & 3.33402 & 6.50668 & 0.42 & 5.93 & $0.0295^{* *}$ \\
\hline $4-3$ & 4.92600 & 12.47444 & 3.58 & 11.52 & $0.0028^{* *}$ \\
\hline $5-1$ & 3.63968 & 5.65805 & -1.01 & 5.05 & 0.1589 \\
\hline $5-2$ & 3.53570 & 7.11147 & 0.24 & 6.91 & $0.0390^{* *}$ \\
\hline $5-3$ & 4.30011 & 9.73323 & 1.59 & 9.27 & $0.0123^{* *}$ \\
\hline
\end{tabular}

*significant at 0.1 level; **significant at 0.05 level 
$[1-2,1-3],[2-2,2-3],[3-1,3-2,3-3],[4-2$, 4-3], [5-2, 5-3] 에서 고안 팔 지지대의 위 아래 손목 각 변화량이 적다는 유의한 차이를 나타내었다.

\section{2 근육부하}

\subsection{1 위쪽 승모근(Upper trapezius)}

실험 결과 표 3 에서와 같이 각 그룹의 세부 과제 중 [2-3], [3-3], [4-3], [5-3]에서 고안 팔 지지대의 근육 부하가 감소한다는, 유의한 차이를 나타내고 있다.

표 3. Paired T-Tests 후 위쪽 승모근의 \%RVC 평균과 $95 \%$ 신뢰구간 및 $p$-value $(\mathrm{n}=8)$

\begin{tabular}{lcrrrr}
\hline \multirow{2}{*}{ 과제 } & \multirow{2}{*}{$\begin{array}{c}\text { 고안 평균 } \\
\text { (\%) }\end{array}$} & 일반 평균 & \multicolumn{2}{c}{$95 \% \mathrm{CI}$} & \multirow{2}{*}{-value } \\
\cline { 4 - 5 } & & & lower & upper & \\
\hline $1-1$ & 14.42331 & 14.12224 & -4.24 & 3.64 & 0.8619 \\
\hline $1-2$ & 23.61063 & 23.42803 & -9.06 & 8.69 & 0.9625 \\
\hline $1-3$ & 36.77178 & 33.48946 & -27.62 & 21.06 & 0.7591 \\
\hline $2-1$ & 22.84375 & 22.51026 & -3.07 & 2.40 & 0.7817 \\
\hline $2-2$ & 33.92200 & 36.31740 & -6.45 & 11.24 & 0.5423 \\
\hline $2-3$ & 41.16540 & 48.80280 & -0.09 & 15.36 & $0.0520^{*}$ \\
\hline $3-1$ & 23.32742 & 25.57363 & -6.72 & 7.21 & 0.9357 \\
\hline $3-2$ & 35.73663 & 41.03033 & -8.99 & 16.33 & 0.5152 \\
\hline $3-3$ & 62.26437 & 91.46221 & 3.95 & 54.45 & $0.0292^{* *}$ \\
\hline $4-1$ & 27.20508 & 27.22476 & -3.46 & 3.50 & 0.9897 \\
\hline $4-2$ & 36.26017 & 36.56009 & -6.73 & 7.33 & 0.9224 \\
\hline $4-3$ & 52.93232 & 76.41922 & 0.02 & 46.95 & $0.0499^{* *}$ \\
\hline $5-1$ & 18.45317 & 19.69839 & -2.50 & 4.99 & 0.4577 \\
\hline $5-2$ & 26.53922 & 28.75842 & -1.46 & 5.90 & 0.1965 \\
\hline $5-3$ & 36.81755 & 41.61908 & 1.43 & 11.42 & $0.0691^{*}$ \\
\hline
\end{tabular}

*significant at 0.1 level; $* *$ significant at 0.05 level

\subsection{2 앞쪽 삼각근(Anterior deltoid)}

실험 결과 표 4 에서와 같이 각 그룹의 세부 과제 중 [2-3], [3-3], [4-3], [5-3]에서 고안 팔 지지대의 근육 부하가 감소한다는, 유의한 차이를 나타내고 있다.

\subsection{3 지신근(Extensor digitorum)}

지신근의 경우 기술적 문제로 인하여 8명의 피실험자 중 1 명을 제외한 7 명의 data를 이용해 분석하였다

실험 결과 표 5 에서와 같이 각 그룹의 세부 과제 중 $[1-2,1-3],[2-2,2-3],[3-2,3-3],[4-2,4-3]$, [5-2, 5-3] 에서 고안 팔 지지대의 근육부하가 감소한다는, 유의한 차이를 나타내고 있다.
표 4. Paired T-Tests 후 앞쪽 삼각근의 \%RVC 평균과 $95 \%$ 신뢰구간 및 $p$-value $(\mathrm{n}=8)$

\begin{tabular}{lrrrrl}
\hline \multirow{2}{*}{ 과제 } & \multirow{2}{*}{ 고안 평균 } & \multirow{2}{*}{ 일반 평균 } & \multicolumn{2}{c}{$95 \% \mathrm{CI}$} & \multirow{2}{*}{\begin{tabular}{l} 
lower \\
\cline { 4 - 5 }
\end{tabular}} \\
\cline { 5 - 6 } & & & upper & \\
\hline $1-1$ & 3.95131 & 3.86516 & -0.50 & 0.33 & 0.6360 \\
\hline $1-2$ & 6.10167 & 7.32248 & -0.35 & 2.79 & 0.1090 \\
\hline $1-3$ & 8.69080 & 9.48181 & -1.50 & 5.08 & 0.2384 \\
\hline $2-1$ & 4.54044 & 5.03922 & -2.11 & 2.85 & 0.7321 \\
\hline $2-2$ & 7.87097 & 7.77924 & -2.58 & 2.39 & 0.9329 \\
\hline $2-3$ & 9.77923 & 12.9685 & 0.17 & 6.21 & $0.0412^{* *}$ \\
\hline $3-1$ & 5.24331 & 6.10631 & -1.74 & 3.47 & 0.4591 \\
\hline $3-2$ & 9.07363 & 9.74056 & -0.84 & 2.17 & 0.3303 \\
\hline $3-3$ & 11.98275 & 17.97471 & 0.37 & 11.62 & $0.0399^{* *}$ \\
\hline $4-1$ & 5.09829 & 5.34899 & -2.33 & 2.83 & 0.8246 \\
\hline $4-2$ & 7.43543 & 8.89099 & -1.35 & 4.26 & 0.2589 \\
\hline $4-3$ & 9.58228 & 13.86764 & 0.63 & 7.94 & $0.0275^{* *}$ \\
\hline $5-1$ & 5.00594 & 5.55647 & -1.43 & 2.53 & 0.5321 \\
\hline $5-2$ & 6.69207 & 7.21286 & -1.84 & 2.88 & 0.6180 \\
\hline $5-3$ & 9.55613 & 12.46205 & -0.04 & 5.85 & $0.0526^{*}$ \\
\hline
\end{tabular}

*significant at 0.1 level; **significant at 0.05 level

표 5. Paired T-Tests 후 지신근의 \%MVC 평균과 95\% 신뢰구간 및 $p$-value $(\mathrm{n}=7)$

\begin{tabular}{|c|c|c|c|c|c|}
\hline \multirow{2}{*}{ 과제 } & \multirow{2}{*}{$\begin{array}{c}\text { 고안 평균 } \\
(\%)\end{array}$} & \multirow{2}{*}{ 일반 평균 } & \multicolumn{2}{|c|}{$95 \% \mathrm{CI}$} & \multirow{2}{*}{$p$-value } \\
\hline & & & lower & upper & \\
\hline $1-1$ & 8.76539 & 8.94305 & -0.54 & 0.89 & 0.5664 \\
\hline $1-2$ & 10.05731 & 11.13441 & 0.09 & 2.07 & $0.0372^{* *}$ \\
\hline $1-3$ & 10.82177 & 13.73258 & 0.21 & 5.16 & $0.0386^{* *}$ \\
\hline $2-1$ & 9.23007 & 9.37535 & -0.77 & 1.06 & 0.7100 \\
\hline $2-2$ & 9.78256 & 11.91027 & 1.12 & 3.13 & $0.0020^{* *}$ \\
\hline $2-3$ & 10.77635 & 14.55625 & 1.75 & 5.81 & $0.0039^{* *}$ \\
\hline $3-1$ & 8.13493 & 8.04283 & -0.80 & 0.61 & 0.7597 \\
\hline $3-2$ & 8.87849 & 10.78445 & 0.14 & 3.67 & $0.0386^{* *}$ \\
\hline $3-3$ & 9.53684 & 14.30840 & 2.35 & 7.19 & $0.0029^{* *}$ \\
\hline $4-1$ & 8.52288 & 8.31342 & -0.57 & 0.15 & 0.2023 \\
\hline $4-2$ & 9.82880 & 11.68711 & -0.32 & 4.04 & $0.0821^{*}$ \\
\hline $4-3$ & 10.70415 & 13.98485 & 1.78 & 4.78 & $0.0017^{* *}$ \\
\hline $5-1$ & 9.80560 & 10.17001 & -0.42 & 1.15 & 0.2991 \\
\hline $5-2$ & 10.85786 & 12.39944 & -0.27 & 3.35 & $0.0825^{*}$ \\
\hline $5-3$ & 11.95177 & 15.50177 & 0.95 & 6.15 & $0.0157^{* *}$ \\
\hline
\end{tabular}

*significant at 0.1 level; **significant at 0.05 level

\subsection{4 척측수근신근(Extensor carpi ulnaris)}

실험 결과 표 6 에서와 같이 각 그룹의 세부 과제 중 
$[1-2,1-3],[2-1,2-2,2-3],[3-2,3-3],[4-3]$, [5-3] 에서 고안 팔 지지대의 근육부하가 감소한다는, 유의 한 차이를 나타내고 있다.

표 6. Paired T-Tests 후 척측수근신근의 \%MVC 평균과 $95 \%$ 신뢰구간 및 $p$-value $(\mathrm{n}=8)$

\begin{tabular}{|c|c|c|c|c|c|}
\hline \multirow{2}{*}{ 과제 } & \multirow{2}{*}{$\begin{array}{c}\text { 고안 평균 } \\
\text { (\%) }\end{array}$} & \multirow{2}{*}{ 일반 평균 } & \multicolumn{2}{|c|}{$95 \% \mathrm{CI}$} & \multirow{2}{*}{$p$-value } \\
\hline & & & lower & upper & \\
\hline $1-1$ & 16.26515 & 17.03716 & -0.99 & 2.53 & 0.3341 \\
\hline $1-2$ & 21.68725 & 23.61693 & -0.14 & 4.00 & $0.0637^{*}$ \\
\hline $1-3$ & 28.27754 & 31.82075 & -0.10 & 7.19 & $0.0551^{*}$ \\
\hline $2-1$ & 22.09233 & 25.18353 & 0.69 & 5.49 & $0.0187^{* *}$ \\
\hline $2-2$ & 27.11183 & 31.96424 & 1.64 & 8.06 & $0.0090^{* *}$ \\
\hline $2-3$ & 34.58015 & 40.85673 & 3.44 & 9.11 & $0.0012^{* *}$ \\
\hline $3-1$ & 23.44341 & 24.54480 & -2.13 & 4.33 & 0.4469 \\
\hline $3-2$ & 30.58876 & 33.06367 & 0.38 & 4.57 & $0.0269^{* *}$ \\
\hline $3-3$ & 36.94439 & 45.41740 & 3.21 & 13.73 & $0.0066^{* *}$ \\
\hline $4-1$ & 20.59325 & 20.50014 & -1.68 & 1.50 & 0.8939 \\
\hline $4-2$ & 23.61855 & 25.67784 & -2.06 & 6.18 & 0.2760 \\
\hline $4-3$ & 32.67542 & 36.38672 & 0.31 & 7.11 & $0.0365^{* *}$ \\
\hline $5-1$ & 22.10794 & 21.71004 & -3.39 & 2.59 & 0.7620 \\
\hline $5-2$ & 27.77029 & 29.89944 & -1.16 & 5.42 & 0.1697 \\
\hline $5-3$ & 37.05279 & 43.20071 & -0.76 & 13.06 & $0.0734^{*}$ \\
\hline
\end{tabular}

*significant at 0.1 level; **significant at 0.05 level

\section{3 주관적 편안함}

실험 결과 표 7에서와 같이 주관적인 편안함이 7 부위 및 몸 전체 모두에서 고안 팔 지지대가 더 편안하다는, 유의한 차이를 보였는데 그 중에서도 특히 손목에서 가장 큰 차이를

표 7. Paired T-Tests 후 주관적 편안함의 차이(고안-일반)에 대한 평균(표준편차)과 $95 \%$ 신뢰 구간 및 $p$-value $(\mathrm{n}=8)$

\begin{tabular}{ccrcc}
\hline \multirow{2}{*}{ 부위 } & \multirow{2}{*}{$\begin{array}{c}\text { 차이 펵균 } \\
\text { (표준편차) }\end{array}$} & \multicolumn{2}{c}{$95 \% \mathrm{CI}$} & \multirow{2}{*}{ lower } \\
\cline { 3 - 4 } & \multicolumn{2}{c}{ upper } & \\
\hline 목 & $0.625(0.85695)$ & -0.14 & 1.39 & $0.0950^{*}$ \\
\hline 어깨 & $1.5 \quad(1.32288)$ & 0.32 & 2.68 & $0.0199^{* *}$ \\
\hline 상박 & $2.125(2.52178)$ & -0.13 & 4.38 & $0.0610^{*}$ \\
\hline 하박 & $2.25(2.53722)$ & -0.02 & 4.52 & $0.0514^{*}$ \\
\hline 손목 & $4.75(1.85405)$ & 3.09 & 6.41 & $0.0003^{* *}$ \\
\hline 손 & $1.625(0.69597)$ & 1.00 & 2.25 & $0.0005^{* *}$ \\
\hline 손가락 & $1.75(1.63935)$ & 0.28 & 3.22 & $0.0256^{* *}$ \\
\hline 몸전체 & $2(1.65831)$ & 0.52 & 3.48 & $0.0153^{* *}$ \\
\hline
\end{tabular}

*significant at 0.1 level; **significant at 0.05 level
보였으며, 그 다음으로 하박, 상박, 손가락, 손, 어깨, 목(몸 전체 제외) 순으로 평균 차가 나타났다.

\subsection{Normal performance}

실험 결과 표 8에서와 같이 각 그룹의 세부 과제 중 [1-3], [2-2, 2-3], [4-2, 4-3], [5-1, 5-2, 5-3] 에서 고안 팔 지지대의 클릭회수가 적다는, 유의한 차이를 나타내 고 있다.

표 8. Paired T-Tests 후 normal performance 에 대한 평균 (표준편차)과 $95 \%$ 신뢰 구간, $p$-value 및 NP ratio $(n=8)$

\begin{tabular}{|c|c|c|c|c|c|c|}
\hline \multirow{2}{*}{ 과제 } & \multirow{2}{*}{$\begin{array}{l}\text { 고안(3분) } \\
\text { 평균클릭수 } \\
\text { (표준편차) }\end{array}$} & \multirow{2}{*}{$\begin{array}{l}\text { 일반(3분) } \\
\text { 평균클릭수 } \\
\text { (표준편차) }\end{array}$} & \multicolumn{2}{|c|}{$95 \% \mathrm{CI}$} & \multirow{2}{*}{$p^{- \text {value }}$} & \multirow{2}{*}{$\begin{array}{l}\mathrm{NP} \\
\text { ratio }\end{array}$} \\
\hline & & & lower & upper & & \\
\hline $1-1$ & $\begin{array}{l}232.4 \\
(56.6)\end{array}$ & $\begin{array}{l}239.4 \\
(48.2)\end{array}$ & -14.45 & 28.36 & 0.4674 & 97.47935 \\
\hline $1-2$ & $\begin{array}{l}189.0 \\
(36.8)\end{array}$ & $\begin{array}{l}200.6 \\
(30.0)\end{array}$ & -6.39 & 29.55 & 0.1715 & 94.74125 \\
\hline $1-3$ & $\begin{array}{l}158.6 \\
(30.0)\end{array}$ & $\begin{array}{l}177.6 \\
(31.8)\end{array}$ & 4.84 & 33.20 & $0.0157^{* *}$ & 89.28988 \\
\hline $2-1$ & $\begin{array}{l}232.2 \\
(52.8)\end{array}$ & $\begin{array}{l}242.6 \\
(48.4)\end{array}$ & -2.92 & 23.71 & 0.1073 & 95.71434 \\
\hline $2-2$ & $\begin{array}{l}179.0 \\
(38.0)\end{array}$ & $\begin{array}{l}204.8 \\
(44.8) \\
\end{array}$ & 4.92 & 46.73 & $0.0223^{* *}$ & 87.39002 \\
\hline $2-3$ & $\begin{array}{l}144.3 \\
(27.6)\end{array}$ & $\begin{array}{l}166.7 \\
(34.8)\end{array}$ & 4.22 & 40.60 & $0.0226^{* *}$ & 86.56027 \\
\hline $3-1$ & $\begin{array}{l}212.3 \\
(65.5) \\
\end{array}$ & $\begin{array}{l}229.5 \\
(57.5) \\
\end{array}$ & -11.42 & 45.85 & 0.1981 & 92.49817 \\
\hline $3-2$ & $\begin{array}{l}173.1 \\
(26.7)\end{array}$ & $\begin{array}{l}184.2 \\
(33.5)\end{array}$ & -6.71 & 29.03 & 0.1834 & 93.97394 \\
\hline $3-3$ & $\begin{array}{l}143.8 \\
(26.4) \\
\end{array}$ & $\begin{array}{l}150.7 \\
(37.1) \\
\end{array}$ & -10.76 & 24.68 & 0.3841 & 95.38368 \\
\hline $4-1$ & $\begin{array}{l}232.5 \\
(46.6)\end{array}$ & $\begin{array}{l}243.3 \\
(35.0) \\
\end{array}$ & -6.22 & 27.82 & 0.1772 & 95.61719 \\
\hline $4-2$ & $\begin{array}{l}180.8 \\
(47.6)\end{array}$ & $\begin{array}{l}201.4 \\
(32.8) \\
\end{array}$ & 1.47 & 39.79 & $0.0383^{* *}$ & 89.75562 \\
\hline $4-3$ & $\begin{array}{l}143.4 \\
(22.5) \\
\end{array}$ & $\begin{array}{l}165.1 \\
(20.2) \\
\end{array}$ & 6.89 & 36.53 & $0.0105^{* *}$ & 86.85070 \\
\hline $5-1$ & $\begin{array}{l}215.0 \\
(35.0) \\
\end{array}$ & $\begin{array}{l}226.1 \\
(30.3) \\
\end{array}$ & 1.76 & 20.52 & $0.0262^{* *}$ & 95.74626 \\
\hline $5-2$ & $\begin{array}{l}178.2 \\
(28.4) \\
\end{array}$ & $\begin{array}{l}197.7 \\
(31.7) \\
\end{array}$ & 1.95 & 37.15 & $0.0341^{* *}$ & 90.11325 \\
\hline $5-3$ & $\begin{array}{l}140.1 \\
(28.3)\end{array}$ & $\begin{array}{l}160.4 \\
(24.6)\end{array}$ & 1.68 & 38.95 & $0.0366^{* *}$ & 87.33693 \\
\hline
\end{tabular}

*significant at 0.1 level; **significant at 0.05 level

\section{5. 추가 실험}

Normal performance의 측정 결과 총 15 개의 세부 과제 중 8개의 세부 과제에서 normal performance가 떨어지는 
것으로 확인되었다. 이에 따라 normal performance의 감 소 원인을 좀 더 자세히 알아보기 위해 추가적으로 실험을 실시하였다.

\section{1 추가 실험 설계}

Normal performance감소의 원인을 찾기 위해 [그림 4] 에서와 같이 세부 과제 수행을 $0.5 \mathrm{cycle}$ 단위에서 분해해 보았다.

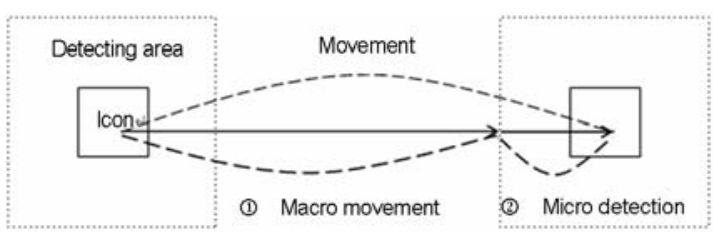

그림 4. Total movement의 분해

그림에서 점선으로 표시한 부분과 같이 먼저 'Detecting area'를 정의하였는데, Detecting area는 아이콘을 중심으 로 아이콘 크기의 가로, 세로 각각 3 배가 되도록 피실험자의 눈에 보이지 않게 설정되었다. 이를 이용하여, 한 아이콘 클 릭 후 다음 아이콘의 Detecting area에 도달하기까지의 움 직임을 'Macro movement', 도달한 직후부터 아이콘을 클릭 할 때까지의 움직임을 'Micro detection'으로 구분하여 각 각의 이동시간을 'Macro moving time(MMT)'과 'Micro detecting time(MDT)'으로 정의하였다. 이에 따라 평균이 동시간(Average of moving time)은 MMT평균과 MDT평 균의 합으로 나타낼 수 있다.

추가 실험은 앞의 본 실험 참가자들로 이루어졌고, 과제는 normal performance에서 유의한 차이가 났던 8개의 세부 과제 ([1-3], [2-2, 2-3], [4-2, 4-3], [5-1, 5-2, 5-3])들로 구성되었다. 실험시간은 세부 과제당 3분씩, 처 음과 중간 중간에 5 초씩의 휴식시간을 주어 총 24 분 40 초 를 1 세트로 하였고, 본 실험과 마찬가지로 balanced된 랜 덤 순서로 고안 및 일반 팔 지지대에서 1 시간 이상의 시간 차이를 두어 실험하였다.

실험을 통해 고안 및 일반 팔 지지대에서 각 세부 과제 별 $\mathrm{MMT}$ 평균과 $\mathrm{MDT}$ 평균, 그리고 [식 2]에서의 정의와 같은 에러율이 피실험자 별로 측정되었다.

$$
\begin{array}{r}
\text { Error rate }=\frac{n}{N} \\
\text { where } n \text { : \# of error } \\
N \text { : \# of click }
\end{array}
$$

[식 2] 에러율의 계산

\section{6. 추가 실험 결과 및 분석}

고안 팔 지지대에서 증가된 $\mathrm{MMT}$ 와 $\mathrm{MDT}$ 의 증가분과 \% 증가분을 각각 위와 아래 그래프로 나타낸 [그림 5]를 보면 두 그래프 모두 세부 과제 1-3에서는 Micro detecting time 이, 나머지 세부 과제에서는 Macro moving time이 normal performance의 감소에 상대적으로 큰 역할을 하였다.

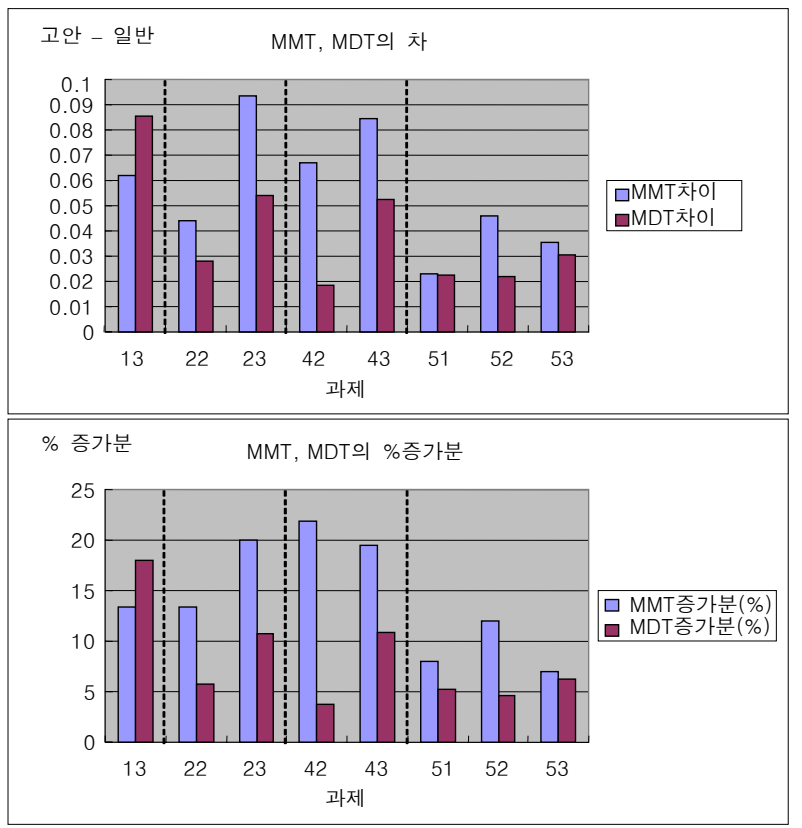

그림 5. $M M T_{\text {diff }}$ 와 $M D T_{\text {diff }}$ 및 \%증가분 plot

세부 과제 1-3과 나머지 과제들 사이에 반대되는 결과가 도출된 점은 세부 과제 1-3만이 추가로 실험한 세부 과제 중 유일한 가로 움직임이라는 특징으로 해석 가능하다. 가로 움직임은 다른 움직임과 달리 팔꿈치가 거의 고정된 축이 되어 좌우로만 움직인다는 특징을 가지고 있다. 따라서 다른 세부 과제들에 비해 MMT가 MDT보다 상대적으로 적었다 고 생각된다. 마지막으로 추가 실험 시 측정한 에러율에서는 고안 및 일반 팔 지지대가 유의한 차이를 나타내지 않았다.

\section{7. 결론 및 추후 연구}

\section{1 손목 움직임}

고안 팔 지지대를 이용한 모든 과제에서 피실험자 전체의 좌우, 위아래 평균 손목 각 변화량이 일반 팔 지지대보다 적 
었으며, 대부분 유의한 결과를 나타내었다. 또한 본지에는 싣지 않았지만 추가로 실시한 Duncan test결과 Deviation angle movement는 고안 및 일반 모두 가로 방향 세부 과제 의 각 변화량이 세로보다 더 크게 나타났다. 하지만 flexion/ extension angle movement에서 고안의 경우 가로, 세로 세 부 과제 그룹간 각 변화량에 있어 유의한 차이가 나타나지 않았다. 그 외에도 오른쪽 아래에서 왼쪽 위로 왕복하는 2그 룹 과제에서 고안 팔 지지대가 Deviation angle movement 를 좀 더 효과적으로 줄여주었다.

\section{2 근육부하}

먼 거리를 움직이는 과제일수록 고안 팔 지지대가 일반 팔 지지대에 비해 측정한 네 부위에서 적은 근육부하를 보였 다. 손목 움직임에서와 마찬가지로 추가로 분석한 Duncan test결과 $\mathrm{UT}, \mathrm{AD}, \mathrm{ECU}$ 에서 고안 및 일반 모두 세로 방향 의 세부 과제가 가로 방향 세부 과제보다 근육부하가 컸고 $\mathrm{ED}$ 의 경우 고안 및 일반 모두에서 과제 그룹 간 근육부하 에 있어 유의한 차이가 나타나지 않았다. UT의 경우 왼쪽 아래와 오른쪽 위를 왕복하는 4그룹 과제에서 2그룹 과제 보다 더 큰 근육부하를 보였으며, ECU의 경우 오른쪽 아래 에서 왼쪽 위로 왕복하는 2 그룹 과제에서 고안 팔 지지대가 근육부하를 좀 더 효과적으로 줄여주었다.

\section{3 주관적 편안함}

선정된 7 부위 및 몸 전체의 주관적 편안함 설문에서 고안 팔 지지대가 더 편안하다는 유의한 차이를 나타내었다.

\subsection{Normal performance}

평소의 마우스 이용 시와 같이 normal condition 하에서 의 performance를 측정해 본 결과 총 15 개의 세부 과제 중 8 개의 과제에서 고안 팔 지지대가 normal performance가 떨어진다는 유의한 결과를 얻었다. 이에 따라 추가 실험을 통해 고안 팔 지지대에서 Normal performance가 떨어지는 원인을 분석한 결과 macro moving time과 micro detecting time 모두 증가를 보였지만, 세부 과제 1-3에서는 MDT가, 나머지 과제에서는 MMT가 전체 moving time 증가에 더 큰 기여를 하는 것으로 나타났다.

추가로 측정한 error rate에서는 고안 및 일반 팔 지지대 의 유의한 차이가 나타나지 않았다.

\section{5 추후 연구}

현재 제안한 팔 지지대는 마우스 이용 시만을 고려하고 설계되었기 때문에 키보드와 마우스를 같이 이용하는 실제 VDT환경에 적용이 용이하지 않다. 따라서 마우스뿐만 아 니라 키보드 이용에까지 효과를 줄 수 있는 통합된 시스템 을 설계하는 것이 다음 단계로 진행되어야 할 것이며, 이 단 계가 되야 실제 VDT환경에서 유용할 것이라 생각된다. 잘 디자인된 시스템은 근골격계 질환의 예방뿐 아니라 performance측면에서도 좀 더 낳은 결과를 가져올 수 있을 것이다.

또한 이번 실험은 새로이 고안된 장비의 효과를 보이기 위해 디자인되었기 때문에 기초적이며 제한된 세부 과제들 을 바탕으로 나타나는 효과를 요소 별로 분석하기 위해 구성 되었다. 하지만 앞으로는 hardware적인 진보와 함께 좀 더 일반적이고 범용적인 과제에서의 실험이 수반되어야 할 것 이고 또한 피로도 실험과 같은 장시간에 걸친 연구 및 현장 에서 적용되는 연구가 수반되면 좋을 것이다.

\section{참고 문헌}

개정 고시 제2004-50호, 영상표시단말기(VDT)취급근로자작업관리 지침, 11, 1, 2004.

안대진, 한국인의 연령을 고려한 VDT workstation 설계. KAIST 석 사논문, 대전, 2004.

Aaras, A., Can a more neutral position of the forearm when operating a computer mouse reduce the pain level for VDU operators?, International Journal of Industrial Ergonomics 30, 307-324, 2002.

Aaras, A., Fostervold, K., Ro, O., Thoresen, M. and Larsen, S., Postural load during VDU work: a comparison between various work postures. Ergonomics 40, 1255-1268, 1997.

Armstrong, T. J., Martin, B. J., Arbor, A., Rempel, D. M. and Johnson, P. W., Mouse input devices and work-related upper limb disorders. Grafica Briantea, Italy, pp. C20-22, 1994.

Basmajian, J. V. and De Luca, C. J., EMG signal amplitude and force in muscles alive 5th Ed., Baltimore, Williams \&Wilkins, 1985.

Bergqvist, U., Wolgast, E., Nilsson, B. and Voss, M., Musculoskeletal disorders among visual display terminal workers: individual, ergonomic and work organizational factors. Ergonomics 38, 763-776, 1995.

Birch, L., Graven-Nielsen, T., Christensen, H. and Arendt-Nielsem, L., Experimental muscle pain modulates muscle activity and work performance differently during high and low precision use of a computer mouse. Eur J Appl Physiol 83, 492-498, 2000.

Cook, C., Burgess-Limerick, R. and Chang, S., The prevalence of neck and upper extremity musculoskeletal symptoms in computer mouse users. International Journal of Industrial Ergonomics 26, 347-356, 2000. 
Cook, C., Burgess-Limerick, R. and Papalia, S., The effect of upper extremity support on upper extremity posture and muscle activity during keyboard use. Applied Ergonomics 35, 285-292, 2004.

Cooper, A. and Straker, L., Mouse versus keyboard use: A comparison of shoulder muscle load. International Journal of Industrial Ergonomics 22, 351-357, 1998.

De Luca., Fundamental concepts in EMG signal acquisition, DelSys Inc, 2001.

Gustafsson, E., Computer mouse use in two different hand positions: exposure, comfort, exertion, and productivity. Applied Ergonomics 34, 107-113, 2003.

Jensen, C., Musculoskeletal symptoms and duration of computer and mouse use. International Journal of Industrial Ergonomics 30, 265 275, 2002.

Jensen, C., Borg, V., Finsen, L., Hansen, K., Juul-Kristensen, B. and Christensen, H., Job demands, muscle actibity and musculoskeletal symptoms in relation to work with the computer mouse. Scand. J. Work Environ. Health 24 (5), 418-424, 1998.

Karlqvist, L., Hagberg, M. and Selin, K., Variation in upper limb posture and movement during word processing with and without mouse use. Ergonomics 37(7), 1267, 1994.

Karlqvist, L., Hagberg, M., Koster, M., Wenemark, M. and Anell, R., Musculoskeletal symptoms among computer-assisted design (CAD) operators and evaluation of a self-assessment questionnaire. Int. J. Occup. Environ. Health 2, 185-194, 1996.

Karlqvist, L., Hagberg, M., Hansson, G.-A., Huld Mattson, G., Neelakantan, G., Skantze, C., Tegelius, B. and Waldenstrom, M., God arbetsmilj.o vid bildsk.armsarbete med datormus i den grafiska branschen (Good working environments for graphic industry VDU operators using a mouse). National Institute for Working life, Arbete och H.alsa, Solna, p. 21(in Swedish), 1995.

Kumar, Electromyography in Ergonomics, Taylor \& Francis Inc, 1996.

Niebel, B. and Freivalds, A., Methods Standards \& Work Design. 10th edition, McGraw-Hill Inc.

Park, M., Ergonomic design and evaluation of a new VDT workstation chair with keyboard-mouse support. International Journal of Industrial Ergonomics 26, 537-548, 2000.
Rempel, D., Johnson, P. and Tal, R., Finger forces measured during computer mouse use. Grafica Briantea, Italy, pp. C28-29, 1994.

Zipp, P., Recommendations for the standardization of lead positions in surface electromyography. European Journal of Applied Physiology 64, 417-420, 1982

\section{저자 소개}

* 박 경 수 * kspark@kaist.ac.kr

미국 미시간대학교, Industrial \& Systems Engineering 박사

현 재: 한국과학기술원 산업공학과 교수

관심분야: 인간공학

* 홍 기 범 * aquaqaz@kaist.ac.kr 한국과학기술원 산업공학과 석사

현 재: 한국과학기술원 산업공학과 박사과정

관심분야: VDT, Ubiquitous, Vision

* 김 상 수 swak4u@kaist.ac.kr

한국과학기술원 산업공학과 석사

현 재: 한국과학기술원 산업공학과 박사과정

관심분야: Computer vision

* 조 일 행 * illy12@hotmail.com

한국과학기술원 산업공학과 석사

현 재: 한국과학기술원 산업공학과 박사과정

관심분야: Ubiquitous systems

논 문 접 수 일 (Date Received) : 2006년 01월 16일

논 문 수 정 일 (Date Revised) : 2006년 03월 31일

논문게재승인일 (Date Accepted) : 2006년 04월 17일 